\title{
Flexural creep behavior of bamboo culm (Phyllostachys pubescens) in its radial direction
}

\author{
Xinxin $\mathrm{Ma}^{1} \cdot \mathrm{Xianmiao} \mathrm{Liu}^{1} \cdot$ Zehui Jiang $^{1} \cdot$ Benhua Fei $^{1} \cdot$ Ge Wang $^{1}$
}

Received: 26 March 2016/Accepted: 1 August 2016/Published online: 26 August 2016

(C) The Japan Wood Research Society 2016

\begin{abstract}
As a construction material, the phenomenon of creep is critical to bamboo structural design. The present work investigates variation of flexural creep behavior of bamboo (Phyllostachys pubescens) in its radial direction. Bamboo specimens were divided into two groups, half of the specimens were loaded by the green side, which fiberrich outer culm wall was in compression (A); the other half were loaded by the yellow side, which fiber-rich outer culm wall was in tension (B). The specimen in both groups were cut into three sections along radial direction, the outer part (A1, B1), the middle part (A2, B2), and the inner part (A3, B3). All specimens were conducted to a $24 \mathrm{~h}$-creep tests. The results show that: The creep resistance of outer part of bamboo is favorable, no matter which kind of loading way. Compared to type A loading with fiber-rich part, specimens of type B loading with fiber-less part showed a higher creep residual strength. The fiber volume fraction was linearly associated with the initial creep of type A and the final creep of type B. It mainly related to the feature and distribution of fiber and parenchyma.
\end{abstract}

Keywords Phyllostachys pubescens - Bamboo · Creep · Orientation

Benhua Fei

feibenhua@icbr.ac.cn

$\triangle$ Ge Wang

super_bamboo@126.com

1 Department of Biomaterials, International Center for Bamboo and Rattan, No. 8, Futong Eastern Street (Futong Dong Dajie), Wangjing Area, Beijing 100102, Chaoyang District, China

\section{Introduction}

Moso bamboo is abundant in many countries, which has excellent mechanical performance. In recent years, engineering use of bamboo as a construction material has begun [1-3]. Thus, the physical and mechanical properties of bamboo has been caught the attention of researchers. As a nature functionally graded material, the properties of bamboo originate from the composition and distribution of the vascular bundles and parenchyma tissues. Therefore, the mechanical properties are closely related to the distribution of vascular bundles.

Several researchers [4-7] discussed the relationship between variation of vascular bundles and mechanical properties of bamboo, which contained bending, shearing, compressing and so on. These results showed that the vascular bundle is significantly higher in the outer side of the culm wall. To model the variation, some basic equations were established to describe the distribution of fibers $[8,9]$. In addition, Obataya et al. [10] observed the relationship between the flexural ductility of split bamboo culm and parenchyma characteristic because of the fine ductile of bamboo. The results indicated that the bamboo was not so flexible elastically but had excellent ductility.

Previous research mainly focused on the mechanical characteristics of bamboo, but there is a little research on the creep behavior of bamboo, which is time dependent property. As a construction material, creep behavior is critical to bamboo structure. It is a potential property, which can affect the serviceability of structure. Kanzawa et al. [11] discussed the relationship between the shape of vascular bundles and creep behavior. It showed that the variation of vascular bundle in cross-section is an important factor. Tsubaki et al. [12] measured the creep of bamboo during desorption. The mechanisms of mechano- 
sorptive behavior were discussed. Gottron et al. [13] studied the effect of the orientation of bamboo specimens to creep behavior. However, in our opinion, it is beneficial to study the creep behavior of bamboo on radial direction through in layers. In this way, it is much convenient and clear to obtain the relationship between variation of vascular bundles and creep.

In this study, we attempted to establish a relationship between microstructure and creep behavior with regard to bamboo fibers. The creep parameters of bamboo were obtained using bending creep tests. The influence of variation of fibers and parenchyma were analyzed. The objective of this study was to further understand the creep behavior of bamboo in its radial direction.

\section{Materials and methods}

\section{Materials}

The bamboo used in this experiment was Moso bamboo (Phyllostachys pubescens), 4-year-old. A typical bamboo specimen was air dried for a few months and then cut into small pieces. All experimental testes were carried out under room temperature and $\mathrm{RH}\left(25 \pm 2{ }^{\circ} \mathrm{C}, 45 \sim 60 \%\right.$ $\mathrm{RH})$ conditions. The samples were chosen from the middle $(1.5 \mathrm{~m})$ of bamboo that the wall-thickness was $12 \mathrm{~mm}$.

\section{Methods}

The variation of fibers across wall-thickness was studied by dividing species into three slices as shown in Fig. 1. The species was cut into three parts with $100 \mathrm{~mm}$ in length, $5 \mathrm{~mm}$ in width and $1.5 \mathrm{~mm}$ in height.

The specimens were divided into two groups, half of the specimens were loaded by the green side, which fiber-rich outer culm wall was in compression (A); the other half were loaded by the yellow side, which fiber-rich outer culm wall was in tension (B). The specimen in both groups was cut into three sections along radial direction, the green part (A1, B1), the middle part (A2, B2), and the yellow part (A3, B3) as shown in Fig. 2. All specimens were tested in three-point bending in an Instron model 5848. The vertical deflection at midspan was measured using a digital depth gauge. All data was collected (a) immediately after

Fig. 1 Geometry of the bamboo specimens
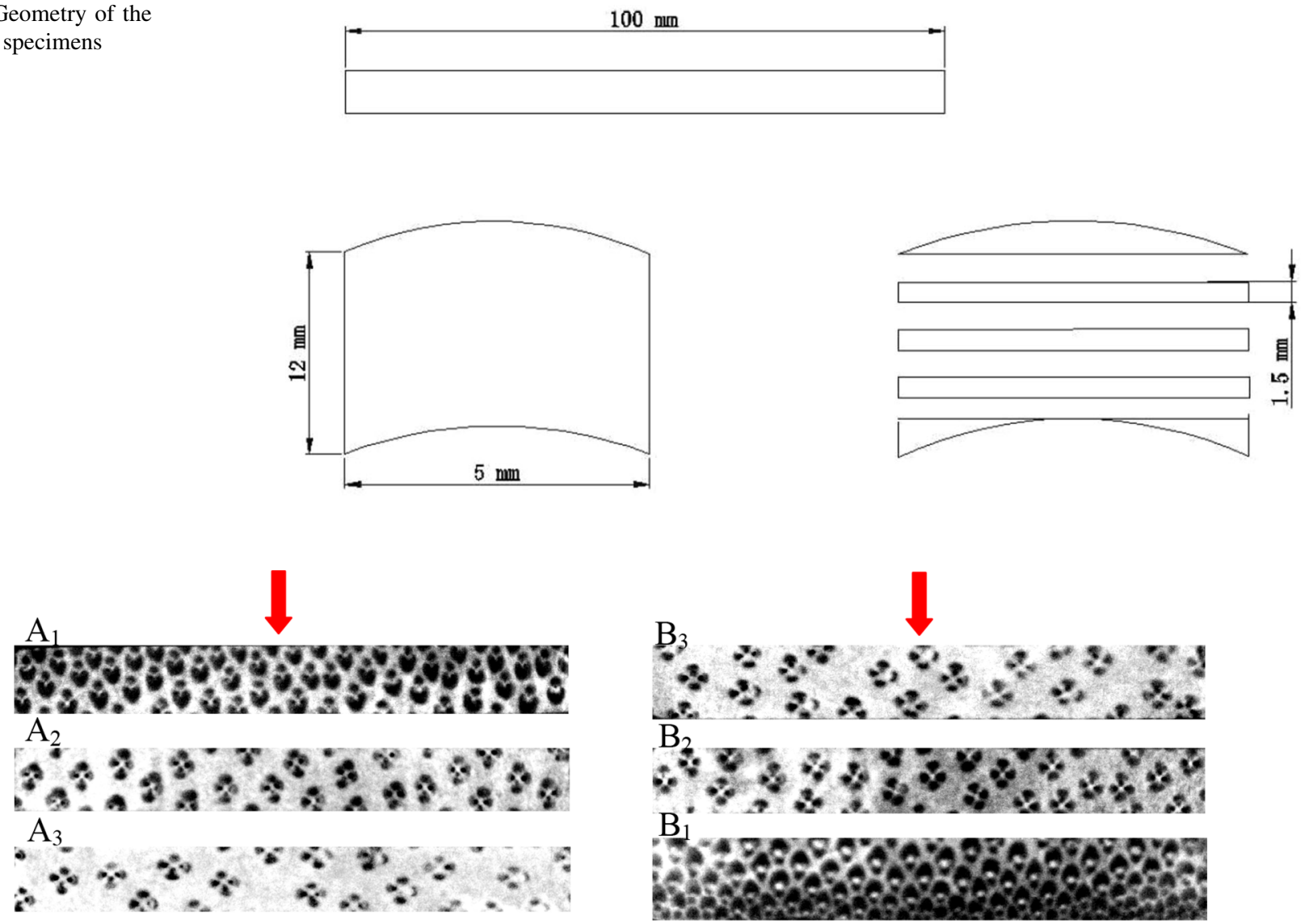

Fig. 2 Different loading ways of bamboo specimens 
loading; (b) every $1 \mathrm{~min}$ for the first hour; (c) every $5 \mathrm{~min}$ for the next $23 \mathrm{~h}$.

To release the internal stress, the specimens were boiled for $30 \mathrm{~min}$ and then put into constant temperature and relative humidity $(\mathrm{RH})$ conditions for 1 week. Creep tests were conducted in three-point bending at room temperature. The creep time was $24 \mathrm{~h}$. The load was $30 \%$ of shortterm ultimate limit state load.

The cross-sections were observed with a microscope, and cross-sectional images were captured using a digital stereo microscope. The fiber volume fraction with respect to position in the culm wall was obtained with image analysis using Image $\mathbf{J}$.

\section{Results and discussions}

\section{Microscopy}

The original image was pre-processed by Image J. The volume fraction of fibers is the ratio of vascular bundle area to total area. In Table 1, it showed the fiber volume fraction of bamboo specimens of two loading ways. The fiber volume fraction included only the extremely dense fibers. The characteristic change in the vascular bundles was related to the position in the longitudinal direction. In addition, the percentage of the fibers was distinctly higher in the outer part $(\mathrm{A} 1, \mathrm{~B} 1)$ of the culm than the inner one (A3, B3).

\section{Creep tests in radial direction}

Before creep test, short-term bending test should be conducted. The loading details can be seen in Fig. 3. Table 1 showed the mechanical properties of bamboo specimens from the outer part to the inner part. Six specimens (3 type $\mathrm{A}$ and 3 type $\mathrm{B}$ ) were tested to failure in three-point bending test. The overall span was 18 times than thickness. The control specimens have the same nominal dimensions as the creep specimens. The size of sample was $100 \mathrm{~mm} \times 5 \mathrm{~mm} \times 1.5 \mathrm{~mm}$. For each group, three specimens were prepared for creep testing.

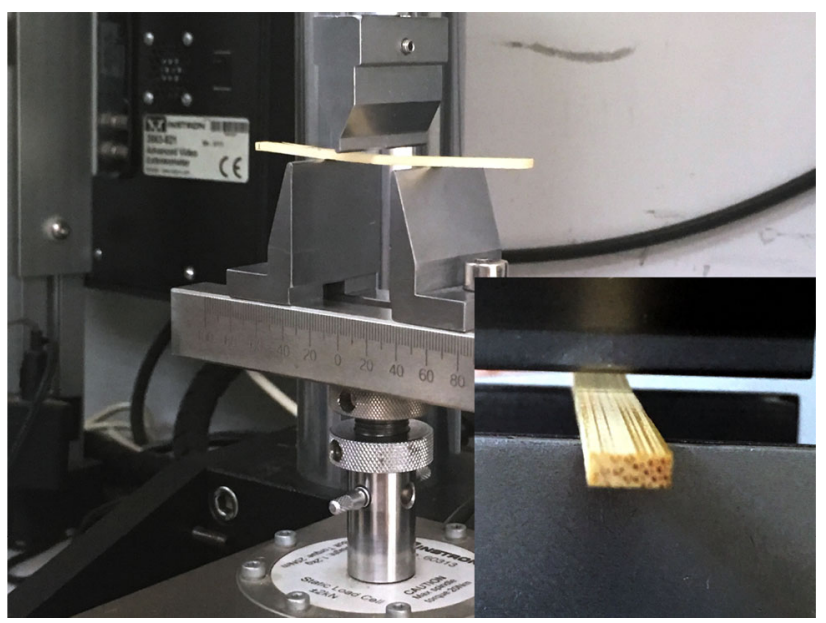

Fig. 3 Loading details

As shown in Table 1, the change law of strength was consistent with the variation of volume fraction of fibers. The data value was obviously higher in the outer part (A1, B1). It is because the percentage of fibers was distinctly higher in the outer part than the inner one. They are failed primarily by fiber tension rupture. Therefore, the modulus and strength of specimens decreased from outer to inner part.

Creep tests were studied then. No specimens exhibited creep rupture during the range of experiment.

To eliminate the interference of the elastic modulus, the relative creep used in this article.

The relative creep $(\varphi(t))$ was defined as:

$\varphi(t)=\frac{\eta(t)}{\eta_{0}}-1$,

in which $\eta_{0}$ and $\eta(t)$ signify the initial deflection and the deflection of the specimen, respectively, after $t$ hours from loading.

Initial creep and final creep are two important factors of creep behavior. Therefore, the focus was on the change rule of these two factors. Relative creep of bamboo loaded by green side and yellow side are showed in Figs. 4 and 5. As shown in Fig. 4, the initial creep of outer layer (A1) was lower than the other two, and the initial creep of specimen A2 was similar with A3. As shown in Fig. 5, the initial

Table 1 The distribution of vascular bundles and mechanical properties

\begin{tabular}{lllllrrr}
\hline Loading way & Type & Fiber volume fraction $(\%)$ & Density $\left(\mathrm{g} / \mathrm{cm}^{3}\right)$ & Average MOR $(\mathrm{MPa})$ & MOE $(\mathrm{GPa})$ & Ultimate load $(\mathrm{N})$ & Creep load $(\mathrm{N})$ \\
\hline Type A & A1 & 53.14 & 0.78 & 201.20 & 12.53 & 160.00 & 48.00 \\
& A2 & 26.17 & 0.54 & 126.71 & 8.77 & 70.00 & 21.00 \\
& A3 & 10.10 & 0.55 & 88.65 & 5.25 & 55.00 & 16.50 \\
Type B & B1 & 38.26 & 1.00 & 280.80 & 19.51 & 164.00 & 49.20 \\
& B2 & 23.89 & 0.85 & 109.04 & 6.23 & 63.00 & 18.90 \\
& B3 & 15.92 & 0.76 & 79.27 & 4.30 & 46.00 & 13.80 \\
\hline
\end{tabular}

MOR modulus of rupture, $M O E$ modulus of elasticity 


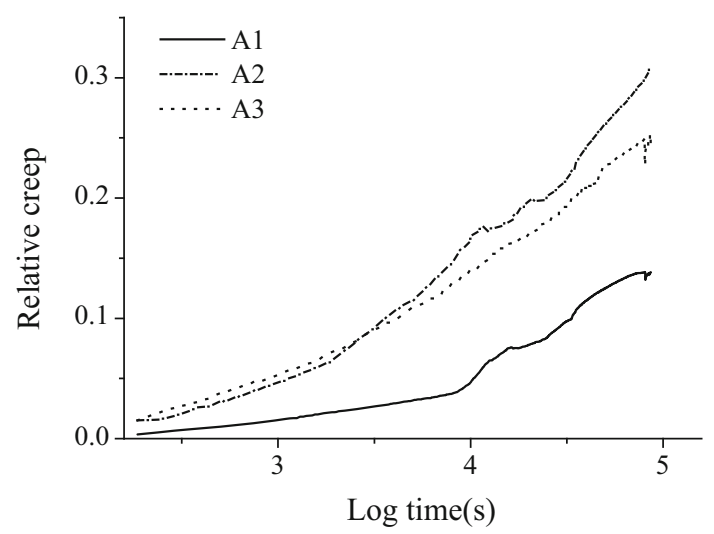

Fig. 4 Relative creep of bamboo in three-point bending loaded from bamboo green side

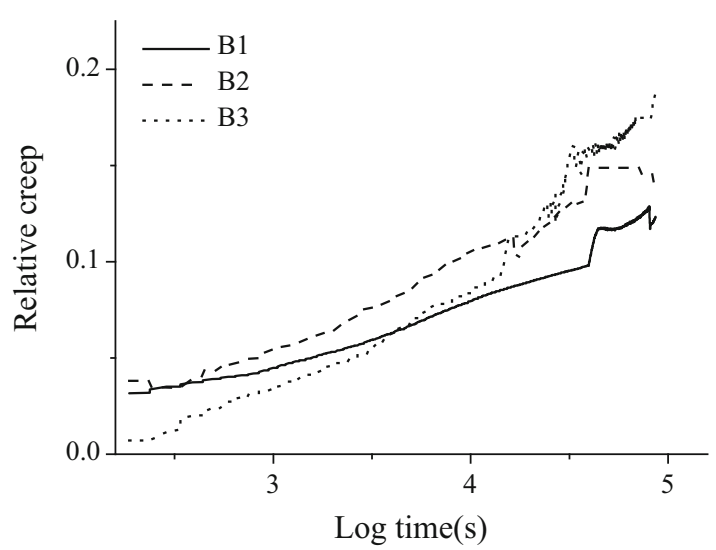

Fig. 5 Relative creep of bamboo in three-point bending loaded from bamboo yellow side

creep of inner layer (B3) was lowest, which different from type A which loaded by green side.

The final value of creep can be used as criteria of the anti-creep properties. From Fig. 4, it showed that the final creep of A1 was lowest, and that of A2 was highest. From Fig. 5, it can be seen that the final creep of B1 was lowest, and that of B3 was highest. In general, the final creep of outer layer was lowest, whether type A or type B, which showed creep resistance of outer layer was best.

Compared loading way of type B, the final relative creep of type A was bigger. It means the creep resistance of specimens of type B was favorable. It indicated that creep deflection can be clearly affected by specimen orientation. This trend may be due to the flexibility of bamboo based on their orientation.

\section{Relationship between fiber volume fraction and creep behavior}

In the longitudinal direction of bamboo, vascular bundles were stretched continuously with rigidity. The percentage

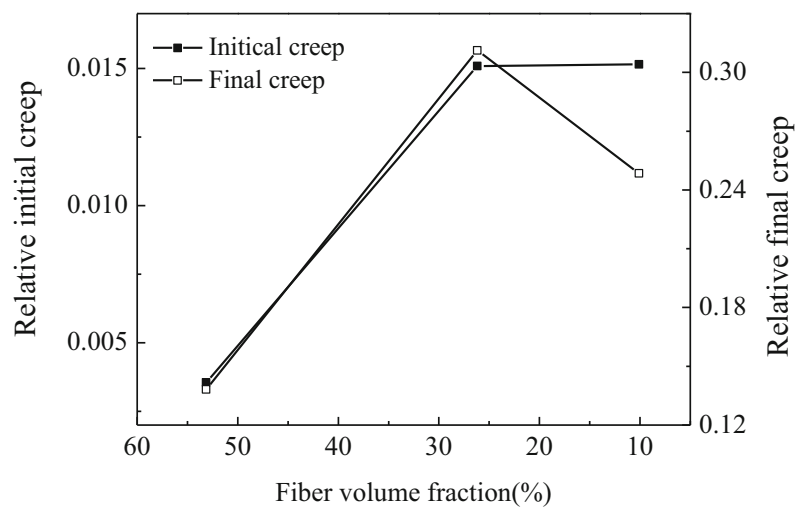

Fig. 6 The relationship of type A between creep and fiber volume fraction

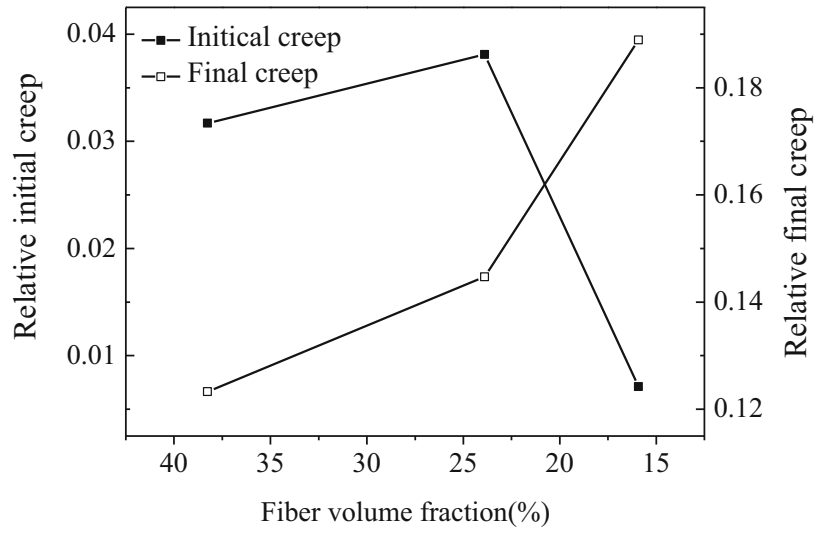

Fig. 7 The relationship of type B between creep and fiber volume fraction

of the fibers is distinctly higher in the outer part than the inner one. Consequently, the creep property of bamboo strongly depend on the volume fraction of fibers. As in Fig. 6, the relationship of type A between the volume fraction of fibers and initial creep, final creep were shown. With the decrease of fiber volume fraction, the values of initial creep increased, A1 $<\mathrm{A} 2<\mathrm{A} 3$. However, there was no significant law of the final creep in type A. This fact suggests that there are definite relationship between initial creep and the fiber volume fraction of type A loading by green side, but no linear relationship with the final creep.

Figure 7 showed the relationship of type B between the volume fraction of fibers and initial creep, final creep. When bamboo loaded by yellow side, the value order of initial creep was: $\mathrm{B} 3<\mathrm{B} 1<\mathrm{B} 2$. There were no obvious law between initial creep and fiber volume fraction. However, the values of final creep of type $B$ were increased with the decrease of fiber volume fraction, $\mathrm{B} 1<\mathrm{B} 2<\mathrm{B} 3$, which was similar to changes of initial creep in type A. This result showed that the final creep of type B loading by yellow side was linearly associated with the fiber volume fraction. 
The bamboo structure consists of vascular bundles embedded in matrix of parenchyma cells. This structure can be considered to be fiber reinforced composites [14]. The groups of vascular bundles are responsible for the bamboo strength. Parenchyma surrounds the vascular bundles, which do not play an important role in the stiffness of bamboo. They acts as matrix and can absorb large compressive deformation owing to its highly compressible foam-like structure. The differences of bamboo creep property which was loaded by two ways mainly due to the loading orientation and fiber distribution. The fiber-rich part is compressed in type A while the fiber-rich part is strained in type B. It is showed that the more the number of fiber, the less the number of parenchyma. The parenchyma can absorb large compressive deformation at initial stage because it has highly compressible foam-like structure. In this stage, the elastic deformations can recover after unloading. However, with time dependent, the parenchyma will be collapsed. This may be the nature of creep property of bamboo with respect to the loading orientation.

\section{Conclusions}

1. The creep resistance of type B loading in the fiber-less part was better than that of type A loading in the fiberrich part. No matter which loading types, creep resistance in the outer layer is better than that in inner layer.

2. For type A, which was loaded in fiber-rich side, there is some regularity between initial creep and the fiber volume fraction, but no linear relationship with the final creep. For type B, loading in fiber-less part, the final creep was linearly associated with the fiber volume fraction. The difference of the creep property of bamboo loaded with different orientation was mainly related to the feature and distribution of fiber and parenchyma.
Acknowledgments This work was supported by International Centre for Bamboo and Rattan, China, and was funded by China's "12th Five-Year Plan" to support science and technology project "Design, Building and Evaluation of Bamboo/Wooden Demonstration Room", Grant No. 2012BAD23B0105.

\section{References}

1. Abdul Khalil HPS, Bhat IUH, Jawaid M, Zaidon A, Hermawan D, Hadi YS (2012) Bamboo fibre reinforced biocomposites: a review. Mater Des 42:353-368

2. Rassiah K, Megat Ahmad MMH (2013) Bamboo, thermoplastic, thermosets, and their composites: a review. Appl Mech Mater 330:53-61

3. Sharma B, Gatóo A, Bock M, Ramage M (2015) Engineered bamboo for structural applications. Constr Build Mater 81:66-73

4. Jain S, Kumar R, Jindal UC (1992) Mechanical behavior of bamboo and bamboo composite. J Mater Sci 27:4598-4604

5. Shao ZP (2004) Mechanical behavior of bamboo with large deformation II: the characteristics of microcosmic deformation (in Chinese). China Wood Ind 18(1):27-29

6. Li HB, Shen SP (2011) The mechanical properties of bamboo and vascular bundles. J Mater Res 26(21):2749-2756

7. Zhou AP, Huang DS, Che SS, Zhang PD (2012) Distribution of vascular bundies of bamboo and its tensile mechanical performances (in Chinese). J Build Mater 15(5):730-734

8. Ghavami K, Rodrigues CS, Paciornik S (2003) Bamboo: functionally graded composite material. Asian J Civil Eng (Build hous) $4(1): 1-10$

9. Dixon PG, Gibson LJ (2014) The structure and mechanics of Moso bamboo material. J R Soc 11(99):1-12

10. Obataya E, Kitin P, Yamauchi H (2007) Bending characteristics of bamboo (Phyllostachys pubescens) with respect to its fiberfoam composite structure. Wood Sci Technol 41:385-400

11. Kanzawa E, Aoyagi S, Nakano T (2011) Vascular bundle shape in cross-section and relaxation properties of Moso bamboo (Phyllostachys pubescens). Mater Sci Eng C 31:1050-1054

12. Tsubaki T, Nakano T (2010) Creep behavior of bamboo under various desorption conditions. Holzforschung 64:489-493

13. Gottron J, Harries KA, Xu QF (2014) Creep behaviour of bamboo. Constr Build Mater 66:79-88

14. Kwan SH, Shin FG, Yipp MW (1987) Consideration of bamboo as a natural composite material (in Chinese). Acta Mater Compos Sin 4(4):79-83 